\title{
CONF-970115-- 8
}

\section{USE OF AN IONS THRUSTER TO DISPOSE OF TYPE II LONG-LIVED FISSION PRODUCTS INTO OUTER SPACE}

\author{
Hiroshi Takahashi and An Yu \\ Brookhaven National Laboratory \\ Upton, New York, 11973
}

(516) 3444099

\begin{abstract}
To dispose of long-lived fission products (LLFPs) into outer space, an ions thruster can be used instead of a static accelerator. The specifications of the ions thrusters which are presently studied for space propulsion are presented, and their usability discussed. Using of a rocket with an ions thruster for disposing of the LLFPs directly into the sun requires a larger amount of energy than does the use of an accelerator.
\end{abstract}

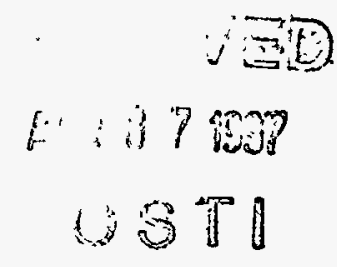

\section{INTRODUCTION}

We proposed an alternative approach to dispose of long-lived fission products (LLFPs) of type II, such as Tc-99 and I-129, into the outer solar space by providing an escape velocity from the solar system of $42 \mathrm{Km} / \mathrm{sec}$ from a parking orbit, or from the moon's surface; this would require the use of an electrostatic accelerator and neutralization of the charged ions (Takahashi 1995).

The LLFP ions must be neutralized to prevent them from being trapped in earth and solar magnetic fields. Launching them from an accelerator, placed at an altitude higher than $170 \mathrm{Km}$, can avoid ionization of the neutralized LLFP atoms so they can pass through the magnetopause boundary, and escape ionization by colliding with atoms in the solar system and in the solar winds, even during periods when the sun's activity is high (Takahashi 1996).

This mode of disposition requires energy in the order of $1 \mathrm{keV}$ for each nucleus, which is far smaller than the propuision energy needed for launching the LLFPs package by rocket. Further, the power required of an accelerator ejecting most of the LLFPs generated by one LWR is $2.2 \mathrm{KW}$, which is much less than a medium energy proton beam power, a few tens of $\mathrm{MW}$, which would be necessary to transmute these LLFPs using spallation neutrons created by protons.

In the last study, we proposed to use a static accelerator with a neutralizer. However, the ions thrusters which have been developed for space propulsion may have the capability to dispose of the LLFP-II.

\section{IONS THRUSTERS}

To dispose of the LLFPs which are generated by one GWe LWR into outer space using an accelerator carried in the space shuttle, a high-current static accelerator of a few hundred to $1 \mathrm{KeV}$ with a neutralizer is required. The ions thrusters which are planned and are being developed to explore solar space are of reasonably high power and specifications, such that they can be used for disposing of LLFPs.

Table 1 shows the main features of the performances of the electrojet thrusters(EJTs) which have been studied by the Russian and European space agencies. Among the most advanced types of electrojet thrusters which could be used for making others that are sufficiently strong for the proposed task are the stationary plasma thrusters (SPTs) of the Russian "Fakel" ("Torch") developmental and design office, and the ion EJT of the EAS-XX type now being developed in Europe. Their electric power is reasonably high, and their life time is 2-3 years. The efficiency of the

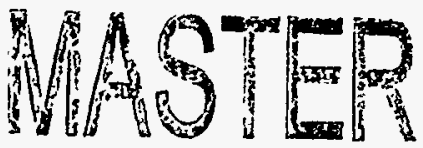


thrusters is high, so that the electric power required to dispose of the LLFPs can be lowered substantially. This is especially true for the Ion EJET of EAS-XX, where the maximum electric power is $6.3 \mathrm{KW}$ and the specific power is $35-60 \mathrm{Km} / \mathrm{sec}$; the efficiency of the EIT is up to $88 \%$, and its operating life time is 15000 hours. These parameters are almost the same as the specifications we proposed for accelerator for disposing of the LLFPs generated by a 1 GWe LWR. Hence, although the LIFP ions are different from the ones used for the ion thruster, we can apply the technology of an ions thruster for material improvement. A high-current ion thruster for many different kinds of ions has been developed by Wilbur's group (Wilbur 1996).

TABLE 1. The Performances of the Electrojet Thrusters.

\begin{tabular}{|l|c|c|c|c|}
\hline \multicolumn{1}{|c|}{ EJT TYPE } & STATTONARY & PLASMA & THRUSTER & ION EJT \\
\hline EJT version & SPT-140 & SPT-200 & SPT-290 & ESA-XX \\
\hline Thrust mN: Nominal & 200 & 500 & 1000 & - \\
\hline Range of regulation & 100.400 & $300 . .700$ & $500 . .1500$ & $100 . .200$ \\
\hline EJT Maximum power, KW & 6 & 12 & 25 & 6,3 \\
\hline Specific impulse, Km/s & 15.5 & 15.31 .5 & $15 . .32$ & 35.60 \\
\hline EJT efficiency & up to 70 & up to 70 & up to 70 & up to 88 \\
\hline Operation life time, hours & 7440 & 18000 & 20000 & 15000 \\
\hline
\end{tabular}

For a simple ions thruster, Miley's group (Miley 1996) is expetimenting with a small ion thruster which has a rather simple configuration; the ions can be ejected directionally by adopting a suitable geometry of the cathode. Although the power is not presently high enough, due to its simple design a high performance could be obtained by a small change.

The ions thruster ejects a neutral beam to avoid charge up in the accelerator. To avoid the capture of LLFP ions by the earth's and sun's magnetic fields, neutralization of the LLFPs should be more complete than is presently attained by the regular ions thruster which is used for propulsion. By re-circulating the non-neutralized ions using a magnet, good quality neutralization could be obtained. The momentum of these ions of mass number 100 and energy of $1 \mathrm{KeV}$ is about $14 \mathrm{MeV} / \mathrm{c}$. The Lamor radius of the ions using the 1-tesla magnetic field is about $5 \mathrm{~cm}$; thus the magnet which recirculates the ions need not be large, and so the device could be loaded into the space shuttle without difficulty.

\section{USE OF AN IONS TRUSTER ROCKET FOR DISPOSING OF LLFPS INTO SUN}

Instead of using the ions thrust as an accelerator, by using it as a rocket engine, we can directly put the LLFPs into the sun by reducing to zero the angular moment of the LLFPs with respect to the sun. The time required by a rocket with an initial velocity $V_{0}$ to reach zero velocity is expressed by:

$$
\text { Mass ratio }=\frac{\text { mass of pay load }+ \text { mass of fuel }}{\text { mass of pay load }}=\exp \left(\frac{V_{0}}{V_{\text {fuel }}}\right)
$$

The mass ratio of the (payload + fuel) to payload is expressed as: 


\section{DISCLAIMER}

This report was prepared as an account of work sponsored by an agency of the United States Government. Neither the United States Government nor any agency thereof, nor any of their employees, make any warranty, express or implied, or assumes any legal liability or responsibility for the accuracy, completeness, or usefulness of any information, apparatus, product, or process disclosed, or represents that its use would not infringe privately owned rights. Reference herein to any specific commercial product, process, or service by trade name, trademark, manufacturer, or otherwise does not necessarily constitute or imply its endorsement, recommendation, or favoring by the United States Government or any agency thereof. The views and opinions of authors expressed herein do not necessarily state or reflect those of the United States Government or any agency thereof. 


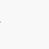

-... 


$$
t=M_{0} \frac{\left(1-e^{\left(-\frac{v_{0}}{v_{s}}\right)}\right)}{\delta M_{0}}
$$

where $\delta \mathrm{M}_{0}$ is the mass ejected in unit time.

Table 2 shows the mass ratio of the ions thruster at various velocities. The mass ratio can be drastically reduced by increasing the velocity of the ions from $5 \mathrm{~km} / \mathrm{sec}$, which is typical of a chemical rocket, to a fuel velocity which is near to the order of the earth's velocity. However, when the ejection velocity is increased to twice the earth's velocity, the reduction in the mass ratio becomes small. The increase in ejecting velocity is not efficient above twice earth's velocity, and an increase in the thrust power is more important for disposing of the LLFPs into the sun.

TABLE 2. Mass Ratio of Ions Thruster Rocket Injected into the Sun.

\begin{tabular}{|c|c|c|}
\hline $\begin{array}{c}\text { FUEL VELOCITY } \\
V_{\text {F KiM/S }}\end{array}$ & $V_{0} / V_{f}$ & MASS RATIO \\
\hline 5 & 6.0 & 403.42 \\
\hline 10 & 3.0 & 20.08 \\
\hline 20 & 1.5 & 4.48 \\
\hline 30 & 1.0 & 2.718 \\
\hline 40 & 0.75 & 2.117 \\
\hline 50 & 0.6 & 1.822 \\
\hline 60 & 0.5 & 1.6 \\
\hline
\end{tabular}

To inject the LIFP payload to the sun, the angular moment of the pay load should be reduced to zero rather quickly. Otherwise, before the angular moment of payload vanishes, the pay load may pass close by the sun, and, gaining velocity from the sun's gravity, it could then fly far away from the sun after circumnavigating it several times. Therefore, a reasonable thrust ions power is required to inject the payload into the sun.

Figure 1 shows the trajectories of an initial rocket with a mass of $10 \mathrm{Kg}$ which is decelerated by using the 1.0 $\mathrm{KW}, 0.5 \mathrm{KW}$, and $0.1 \mathrm{KW}$ ions thruster with $30 \mathrm{Km} / \mathrm{sec}$ specific velocity. When the $1.0 \mathrm{KW}$ power thruster is used, the payload can be injected into the sun after 70 day of operation; but, for the $0.5 \mathrm{KW}$ power thruster, the payload would circle half around the sun, and after gaining velocity due to the sun's gravity, would fly away at high speed. Due to the conservation of angular momentum, after many years of travel far from the sun, it would come back, near to the sun. If we give the payload a small angular momentum using a small thrust when it is far from the sun, then the pay load would be moved away from the sun's gravity space, and would not return. When we use the $0.1 \mathrm{KW}$ power thruster, after circulating the sun several times, the pay load would then fly away. This simple calculation of trajectory does not take into account earth's gravity; but, by using the earth's gravity, we might save some of the energy required to disposition the LLFPs into the sun.

The total amount of LLFPs generated by running a 1 GWe power LWR is about $74 \mathrm{Kg}$ per year. To put this amount of the LLFP into the sun by running an ions thruster with a specific velocity of $30 \mathrm{~km} / \mathrm{sec}$ for 70 days, a thruster of $74 \mathrm{Kg}^{*} 2.718 * 1 \mathrm{KW} / 10 \mathrm{Kg}=20.1 \mathrm{KW}$ power is required, at a minimum. The amount of energy needed, $20.1 \mathrm{KWx} 70$ day=1.41 MWday, is higher than the power required for disposing uniformly of the LLFPs using an accelerator which gives $2.84 \mathrm{KW} * 365$ day $=1.03 \mathrm{MW}$-day; further, this does not take into account the mass of the electro-thruster and the fuel required for generating its electric power. 


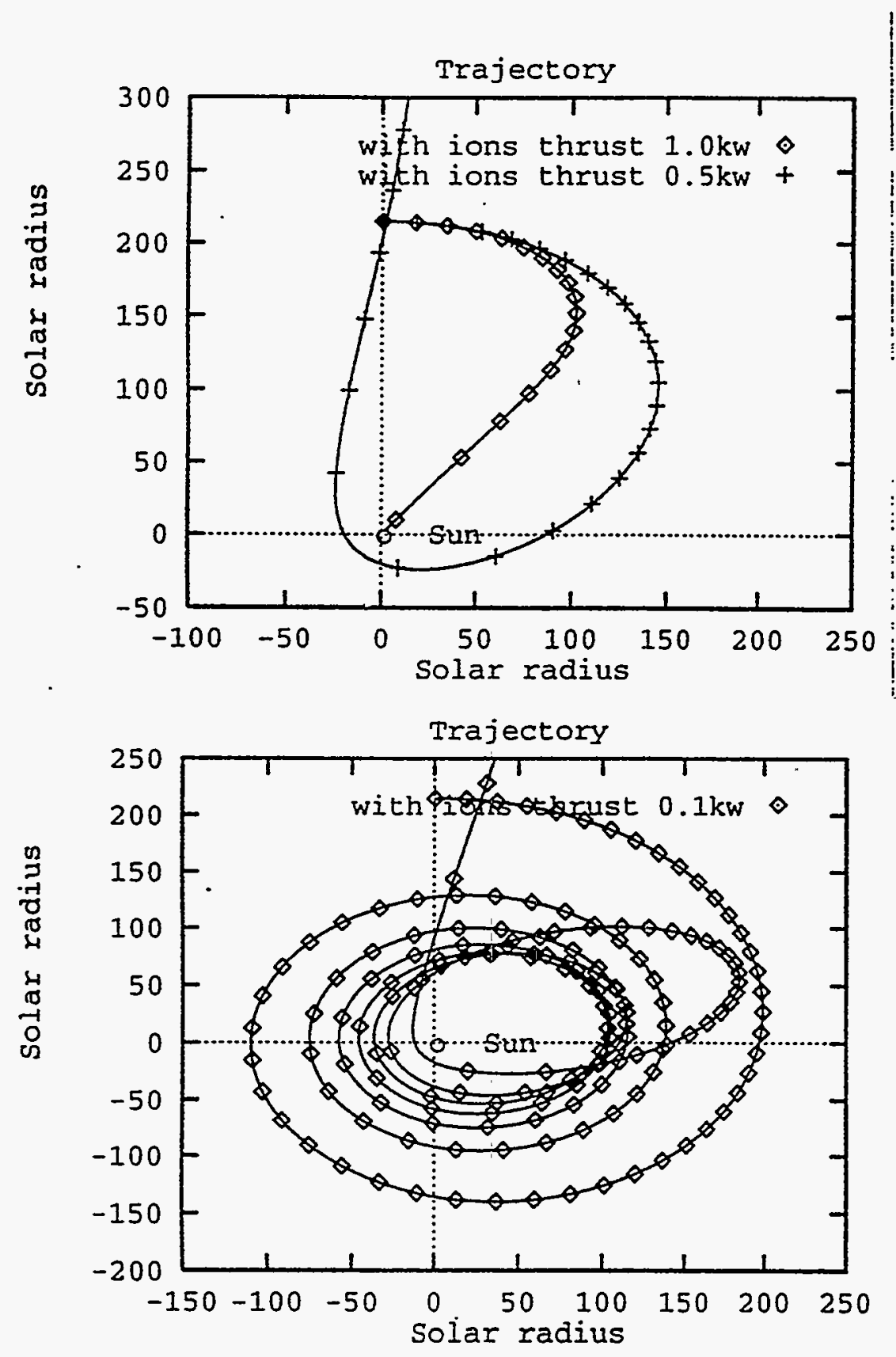

FIGURE 1. Trajectory of the Ions Thruster Rocket with Powers of 1.0, 0.5, and $0.1 \mathrm{KW}$.

\section{SAFETY ISSUES DUE TO A LAUNCHING FAILURE OF THE LLFPS}

There is much concern about the possibility of a failure when launching LLFPs from the earth. To protect the astronauts, NASA extensively studied the shielding of the rad-wastes which will be loaded into the space shuttle. Experiments were performed by dropping the capsule with its heavy shield material on to hard and soft ground surfaces; damage to the payload was examined to evaluate its impact in a launching failure (NASA 1974). In contrast to previous studies for disposing of whole rad-waste, our payload is only LLFPs and it contains no shortlived fission products (SLFP), such as Cs-137 and Sr-99, nor minor actinides; thus, its radioactivity is far less than these rad-wastes. 
Table 3 shows the radioactivity of LLFPs generated by running a 1 GWe power plant for 1 year, this value also is less than the radioactive material Pu-238, which is planned for use for the Cassini mission. The radioisotope thermoelectric generator (RTG) of Pu-238 produces 265 watt (Mukunda 1995), and the radioactivity of this Pu-238 is about 1000 Curies, compared to about 500 Curies of our LLFPs.

TABLE 3. Radioactivity and Decay Products of LLFPs, and ${ }^{93} \mathrm{Zr}$ Generated by a Standard LWR Per Year.

\begin{tabular}{|c|c|c|c|c|c|}
\hline ISOTOPE & DECAY & $\begin{array}{c}\text { HALF LIFE } \\
\text { (YEAR) }\end{array}$ & $\begin{array}{c}\text { RADIATION } \\
\text { SOURCE }\end{array}$ & $\begin{array}{c}\text { DECAYED } \\
\text { PRODUCT } \\
\text { (Ci) }\end{array}$ & $\begin{array}{c}\text { Qbeta }^{-} \\
\text {MeV }^{-1}\end{array}$ \\
\hline${ }^{79} \mathrm{Se}$ & beta & $6.5 \mathrm{E} 4 \mathrm{a}$ & 13.75 & $79_{\mathrm{Br} \text { (stable) }}$ & 0.16 \\
\hline${ }^{93} \mathrm{Zr}$ & beta & $1.6 \mathrm{E} 6 \mathrm{a}$ & 61.39 & ${ }^{93_{\mathrm{Nb}} \text { (stable) }}$ & 0.06 \\
\hline $99 \mathrm{Tc}$ & beta & $2.13 \mathrm{E} 5 \mathrm{a}$ & 433.6 & $99_{\mathrm{Ru} \text { (stable) }}$ & 0.2936 \\
\hline $107 \mathrm{Pd}$ & beta & $6.5 \mathrm{E} 6 \mathrm{a}$ & 3.73 & $107_{\mathrm{Ag} \text { (stable) }}$ & 0.0331 \\
\hline $129 \mathrm{I}$ & beta & $1.57 \mathrm{E} 7 \mathrm{a}$ & 1.03 & $129 \mathrm{Xe}$ (stable) & 0.192 \\
\hline $135 \mathrm{Cs}$ & beta & $2.3 \mathrm{E} 6 \mathrm{a}$ & 8.83 & $135_{\mathrm{Ba} \text { (stable) }}$ & 0.21 \\
\hline
\end{tabular}

Instead of launching of these LLFP with a chemical rocket, we might use another launcher (Morse 1996), such as an electro-magnetic gun (rail gun) (Turman, Lipinski 1996); the advantages are the light payload and light shielding requirement. Presently, the maximum speed of the projectile is limited, at the most, to a few $\mathrm{km} / \mathrm{sec}$, that is not sufficient for putting the LLFPs into solar outer space; it might suffice for launching the LLFPs cargo into parking orbit, for which the needed velocity is about $4 \mathrm{Km} / \mathrm{sec}$. A small mass of LLFPs can be launched economically by an electro-magnetic force. After sending them into earth orbit, they can be transported from parking orbit, in a transporting vehicle, to the space shuttle which is equipped with accelerator. Using these launchers, such as the big gun, or the two-stage hydrogen-driven gun, the electromagnetic gun can be a safer way to launch the LLFPs than with chemical rockets.

\section{SUMMARY}

We explored whether an ion accelerator, boarded on the space shuttle, could dispose of LLFPs into outer space with much less energy than the one used for transmuting LIFP by spallation neutrons. The ion thruster which has been developed for interplanetary space exploration could be used for accelerating the LLFP ions instead of the static ion accelerator proposed in our last paper. When we use the ions thruster rocket to dispose of LLFPs into the sun, but without taking into account the load of the thruster engine and the fuel used, then the energy required to dispose only of LLFPs becomes comparable to that of accelerating LLFPs from the space shuttle. However, if these loads are accounted for, disposing of the LLFPs directly into outer space from the space shuttle is more efficient than using the ions thruster rocket.

\section{Acknowledgments}

The author would like to express his thanks to Drs. K. Goodfellow, J. Polk (Jet Propulsion Laboratory), V. Kim, V. Tikhov (Moscow Aviation Institute) and V. Andreev (Energocosmos), for their valuable discussion and for providing him with the information for writing this report, and to A.D. Woodhead for the editorial work. This work was performed under the auspices of the U.S. Department of Energy under Contract No. DE-AC02$76 \mathrm{CH} 00016$. 


\section{References}

Andreev, P.V., et al (1996) " State and Outlooks of Space Thermionic Reactors Development and Application," Report presented at "The Eighth International Conference on Emerging Nuclear Energy System ("ICENE-96") Obninsk, Russia June 24-28,1996.

Bonnaue, P., H. Rief, P. Mandrillon, and H. Takahashi (1987) "Actinide Transmutation by Spallation in the Light of Recent Cyclotron Development," NEACRP-A-910, Session B.1.2, (European American) Reactor Physics Committee Report.

Egorov, N.N. et al. (1991), "Fuel Management in the USSR and New Way to Solve the Problem," in Moscow Radio-Technical Institute of the USSR Academy of Sciences. "Atomic Energy Industry Radioactive Waste Handling Problem," ISBN 5-201-09424-4.

Kim, V. and V. Tikhonov (1996) "Development of the Powerful Electric Propulsion Thrusters in Russia," in Seventh Advanced Space Propulsion Workshop, Jet Propulsion Laboratory, April 9-11, 1996.

Miley, G. et al (1996) "A Novel IEC Propulsion Unit for Satellite Applications," in AIP Conference Proc. 361, 1435.

Morse Thomas (1996) " Electromagnetic Launch, Then Lessening Chemical Thrust over Time as Laser Beam Powered Ion Thrust Grows to Any Orbit," in AIP Conference Proc.361, 683.

Mukunda, M. (1995) "An Assessment of the Response of the GPHS-RTG to Potential Accident Environments," in AIP Conference Proc.324, 361.

National Aeronautic and Space Administration, (Lewis Research Center) (1974) "Feasibility of Space Disposal of Radioactive Waste," in II- Technical Summary. NASA report TMX-2912, May, 1974.

Takahashi, H., N. Mizoo, and M. Steinberg; (1980) "Use of Linear Accelerator for Incinerating the Fission Product of Cs- 137 and Sr-90," in Inter. Conf. on Nuclear Waste Transmutation, The Univ. of Texas at Austin, July 22-24, 1980.

Takahashi, H., (1985) "Actinide Transmutation by the Spallation Process," presented at Workshop on the Feasibility of Research Program in Actinide Transmutation by Spallation Process, Euratom, Ispra, Varese, Italy, June 18-21, 1985.

Takahashi, H. (1992), "The Use of Minor Actinides and a Small Power Proton Accelerator for fast Reactor with a High Breeding Gain. (Alternate Ways to Dispose of High Level Waste: The Merits of the Antaretic Ice-field, the Moon, and Outer Space)," in Proc. of the Specialist's Meeting on the Accelerator Based Transmutation PSI, Villigen, Switzerland. PSI Proc 92-02.

Takahashi, H. and X. Chen (1995) "Alternate Way to Dispose of High Level Waste in Outer Space," in AIP Conference, Proc. 324: 347-354.

Takahashi, H. and X. Chen (1996) "Disposal of Type -II Long-lived Fission Products into Outer Space," in AIP Conference, Proc. 361: 967-973.

Turman, B.N. and Lipinski, R.J. (1996) " Electromagnetic Coil-gun Launcher for Space Applications, in $A I P$ Conference Proc. 361, 703.

Wilbur, P. (1996) " Dual-use Application of Ion-thruster Technology," in AIP Conference Proc. 361, 155. 


\section{DISCLAIMER}

Portions of this document may be illegible in electronic image products. Images are produced from the best available original document. 
. 